\title{
Protoilludane sesquiterpenoids as scaffold structures for new antimicrobials against Mannheimia haemolytica
}

\author{
Gemma Assante $^{1}$, Sabrina Dallavalle ${ }^{2}$ and Piera Anna Martino ${ }^{3}$ \\ The Journal of Antibiotics (2013) 66, 43-45; doi:10.1038/ja.2012.90; published online 24 October 2012
}

Keywords: antimicrobial activity; Escherichia coli; pasteurestins; sesquiterpenes; structure-activity relationships; tsugicoline

Research on the overall chemistry of basidiomycetes has led to the discovery of a wealth of secondary metabolites with rich variation of structures and novel carbon skeletons. ${ }^{1}$ Some compounds have found medical applications as lead structures for the development of pharmaceutical products, starting material for agrochemicals or antibiotics. ${ }^{2}$ Indeed, new antibiotics are continuously needed to counteract resistance of newly evolved pathogens and/or toxicity and allergic reactions of some of the current compounds. ${ }^{3,4}$

Recently, two novel protoilludane sesquiterpenoids, named pasteurestins A and B (1 and 2 in Figure 1), have been isolated and characterized. ${ }^{5}$ Both compounds were obtained by fermentation of the basidiomycete Agrocybe aegerita and were reported to show strong and selective activity against two strains of Mannheimia haemolytica, a pathogen causing bovine respiratory disease. Particularly, M. haemolytica is the principal bacterium isolated from respiratory disease in feedlot cattle and represents an important component in enzootic pneumonia in neonatal calves. ${ }^{6}$

This property made pasteurestins interesting as potential antibiotics in veterinary applications. Inspired from their biological activity, we were intrigued to evaluate suitable analogs as antimicrobials. The two pasteurestins are characterized by a highly strained hydrocyclobutaindane nucleus with five stereogenic centers. The complexity of the structures hampers the preparation of analogs by chemical synthesis. Indeed, Mulzer and collegues ${ }^{7}$ have developed an elegant total synthesis of pasteurestins, consisting however of 20-22 linear steps with a $0.5-0.8 \%$ overall yield.

As part of our work on the search for unexplored resources, we have extensively investigated specific strains of basidiomycetes, such as species of Armillaria, Clitocybe, Clavicorona and Echinodontium (formerly classified as Laurilia). A large number of the characterized bioactive secondary metabolites belong to the group of sesquiterpenes. Typically, they present a differently substituted protoilludane skeleton to form a multitude of transformed and rearranged tricyclic compounds. ${ }^{8-17}$ Among the isolated compounds, we selected those more structurally related to pasteurestins (compounds 3-14 in Figure 1) and available in sufficient amounts to perform antimicrobial tests. The antimicrobial activity was tested against $M$. haemolytica ATCC 14003, Pasteurella multocida ATCC 15743 and Escherichia coli ATCC 25922.

All the compounds showed no activity against $P$. multocida (for details see Supplementary Information). Similarly, Sulcatine $\mathrm{A},{ }^{10}$ Tsugicoline E, ${ }^{12}$ Melledonale C, ${ }^{13}$ 3-epi illudol, ${ }^{8}$ illudalic acid, ${ }^{15}$ illudine $\mathrm{M}^{16}(3,7,9), 13^{13}$ and $14^{17}$ were not active against $M$. haemolytica (MIC $128-256 \mu \mathrm{g} \mathrm{ml}^{-1}$ ). On the contrary, Sulcatine $\mathrm{B},{ }^{11}$ Tsugicoline A, ${ }^{9}$ Tsugicoline $C^{9}(\mathbf{4 - 6})$ and $\mathbf{8}^{18}$ showed significant activity against $M$. haemolytica ( $\mathrm{MIC} 32 \mu \mathrm{g} \mathrm{ml}^{-1}$ ). It is interesting to notice that the absence of a $-\mathrm{CH}_{2} \mathrm{OH}$ group (3 vs 4 ) and a different fusion of rings (14) caused a complete loss of activity. The MIC against E. coli was $32 \mu \mathrm{g} \mathrm{ml}^{-1}$ for all the compounds tested (3-14).

These findings are noteworthy, as Takeuchi et al. ${ }^{5}$ reported an MIC of $0.78 \mu \mathrm{g} \mathrm{ml}^{-1}$ for pasteurestin $\mathrm{B}$, whereas in the antimicrobial tests performed by Mulzer and collegues ${ }^{7} M$. haemolytica and E. coli remained unaffected by synthetic pasteurestins.

The promising results prompted us to select one of the most active compounds, Tsugicoline A (5) to delineate the essential structural requirements for activity against $M$. haemolytica. As the complexity of the molecule excluded total synthesis, we focused on its isolation from natural sources. The need for consistent amounts of the natural product to prepare differently substituted derivatives required the choice of a good producing strain and the optimization of the fungal growth conditions. Tsugicoline A was the major metabolite isolated from the fungus Echinodontium tsugicola (Henn. \& Shirai) Imazeki supplied as CBS $248.51 .^{9}$ A second strain of E. tsugicola was kindly supplied by Dr Yoshihito Shiono (Department of Bioresource Engineering, Yamagata University Japan, Yamagata, Japan). ${ }^{19}$ Unlike mitosporic fungi, some basidiomycetes are not easy to cultivate on 


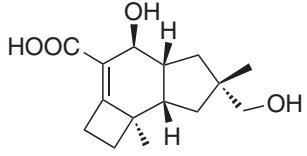

1

Pasteurestin A<smiles>CC1(C)C[C@H]2[C@@H](C1)[C@@H](O)C(CO)=C1C(=O)[C@@H](O)[C@]12C</smiles>

5

Tsugicoline A

$(32 \mu \mathrm{g} / \mathrm{mL})$

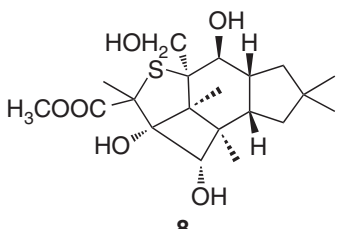

(32 $\mu \mathrm{g} / \mathrm{mL})$<smiles>CC1(C)Cc2c(O)c(O)c3c(c2C1)C(=O)OC(O)C3</smiles>

11

Illudalic acid $(256 \mu \mathrm{g} / \mathrm{mL})$<smiles>CC1(C)C[C@@H]2[C@H]([C@H]1O)[C@@]1(C)CCC1=C(C(=O)O)[C@@H]2O</smiles>

2

Pasteurestin B

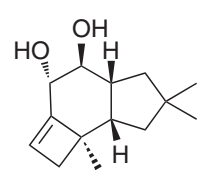

3

Sulcatine A

$(256 \mu \mathrm{g} / \mathrm{mL})^{\mathrm{a}}$

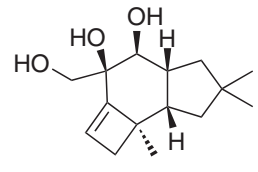

4

Sulcatine B

(32 $\mu \mathrm{g} / \mathrm{mL})$<smiles>CC1(C)C[C@H]2[C@@H](C1)[C@@H](O)C(CO)=C1[C@@H](O)[C@@H](O)[C@]12C</smiles>

6

Tsugicoline C

(32 $\mu \mathrm{g} / \mathrm{mL})$

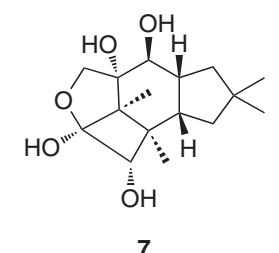

Tsugicoline $\mathrm{E}$ $(256 \mu \mathrm{g} / \mathrm{mL})$<smiles>COc1cc(O)c(C(=O)O[C@@H]2C[C@@]3(C)C4[C@H](O)C(C)(C)C[C@]4(O)C=C(C=O)[C@@]23O)c(C)c1Cl</smiles>

9

Melledonale C

(256 $\mu \mathrm{g} / \mathrm{mL}$ )<smiles>CC1(C)C[C@H]2[C@@H](C1)[C@@H](O)C(CO)=C1C[C@H](O)[C@@]12C</smiles>

10

3-epi-Illudol

$(128 \mu \mathrm{g} / \mathrm{mL})$<smiles>CC1=C2C(=O)C(C)(O)C3(CC3)C2=CC1(C)C</smiles>

12

Illudine M $(256 \mu \mathrm{g} / \mathrm{mL})$<smiles>C[C@]1(CO)Cc2cc3c(cc2C1)C(=O)OC3</smiles>

13

$(256 \mu \mathrm{g} / \mathrm{mL})$<smiles>CC1=CC(=O)C(O)(CO)C(O)C1CC(C)(C)C</smiles>

14

(256 $\mu \mathrm{g} / \mathrm{mL})$

Figure 1 Structures of Pasteurestins A and B and related sesquiterpenes tested. aln brackets are the reported MIC values against M. haemolytica.

substrates at high nutrient availability and high concentrations of simple monomeric nutrients (mono- or oligo-saccharides and aminoacids), as the development of mycelium in such artificial systems is negatively affected. Similarly, submerged cultivation (liquid culture and fermenter) and cultivation duration may influence the type and the production of the secondary metabolites. In our previous experiments, tsugicolines $\mathrm{A}-\mathrm{D}$ were produced by E. tsugicola in Erlenmeyer flasks containing malt extract broth. ${ }^{9}$ The optimization of the amount of tsugicolines A produced by the fungus was obtained by screening several substrates containing different sugar/peptide ratio and we found the best substrate to be a carbohydrate-rich broth enriched till $2 \%$ glucose. Introducing a pre-culture step at mild osmotic stress led to faster production of secondary metabolites, compared with previous experiments (see Supplementary Information). Altough both strains of E. tsugicola produced tsugicolines, differences in amount of production between them were observed. The crude extract obtained from the Japanese strain $\left(750 \mathrm{mg} \mathrm{l}^{-1}\right)$ was greater than that of CBS strain $\left(530 \mathrm{mgl}^{-1}\right)$, but tsugicoline A (106 $\mathrm{mgl}^{-1}, 20 \%$ crude extract) was more abundant in CBS strain than in the Japanese one, which produced only $2.3 \%$ $\left(17.5 \mathrm{mgl}^{-1}\right)$. The compound mainly occurred in the liquid medium as the mycelium, dried and extracted separately, contained only traces of tsugicolines. E. tsugicola CBS strain produced tsugicolines in liquid more than in agar cultures of the same medium $\left(72 \mathrm{mgl}^{-1}\right)$ where tsugicoline A represented only $7 \%$ of the crude extract. Solid state fermentation was not tried.

With the natural compound in hands, we planned to introduce modifications on the reactive groups of the molecule to perform initial structure-activity relationship studies.

We first tried to obtain a derivative with a carboxylic group on C-1, as in the pasteurestins, but several attempts to oxidize tsugicoline $\mathrm{A}$ ( $\mathrm{NaOCl}$-supported-TEMPO, NCS -supported TEMPO, $\mathrm{MnO}_{2}$ ) were unsuccessful and gave inseparable mixtures of compounds. The introduction of the formyl group was accomplished only by treatment of 5 with TEA in $\mathrm{MeOH}$ to give compound 16, most likely formed by the intermediate formation of an enolate, followed by water elimination ${ }^{9}$ (Figure 2). Further oxidation or catalytic reduction ${ }^{20}$ of aldehyde 16 gave rise to complex mixtures of reaction products, thus confirming the sensitivity of this class of compounds to different reaction conditions.

Compound 17 was obtained by reduction of the carbonyl group with $\mathrm{NaBH}_{4},{ }^{17}$ whereas treatment of 5 with $\mathrm{Ac}_{2} \mathrm{O}$ and pyridine at $0{ }^{\circ} \mathrm{C}$ afforded the corresponding triacetoxyderivative $\mathbf{1 8}$.

Finally, reaction of $\mathbf{5}$ with different hyrdoxylamines gave the corresponding oximes 19a-c. Compounds 16 and 17 showed good 


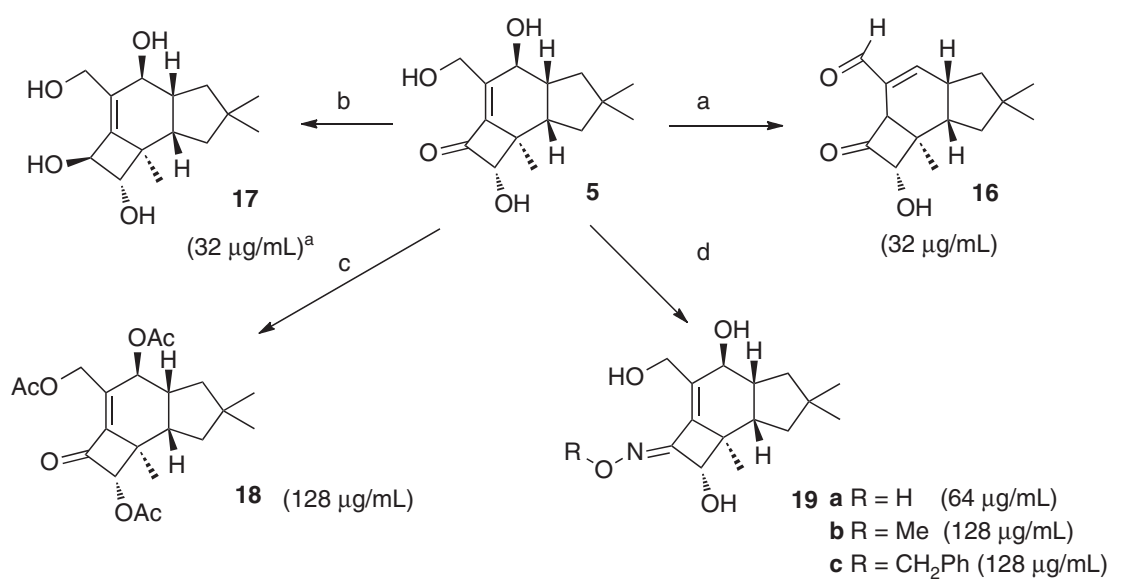

Figure 2 Synthesis of Tsugicoline A derivatives. Reagents and conditions: (a) TEA, methanol, $4 \mathrm{~h}$, room temparature, 43\%; (b) $\mathrm{NaBH}_{4}$, methanol, $2 \mathrm{~h}$, room temparature, $79 \%$; (c) acetic anhydride, dry pyridine, $0^{\circ} \mathrm{C}, 6 \mathrm{~h}, 41 \%$; (d) $\mathrm{RONH}_{2} . \mathrm{HCl}, \mathrm{NaH}_{2} \mathrm{PO}_{4}, \mathrm{MeOH}$, room temparature, overnight.

activity (MIC $32 \mu \mathrm{g} \mathrm{ml}^{-1}$ ), whereas compounds 18 and 19a-c inhibited the growth of M. haemolytica with an MIC between 64 and $128 \mu \mathrm{g} \mathrm{ml}^{-1}$.

These results allowed us to delineate some preliminary structureactivity relationship. First, they highlight the importance of the polar functions on C-1 and C-6. In fact, the introduction of the formyl group on C-1 retains the antimicrobial activity (16 vs $\mathbf{5}$ ), even if the $\mathrm{OH}$ on $\mathrm{C}-3$ is removed, whereas acetylation of the three hydroxyl groups causes a decrease of the activity (18 vs $\mathbf{5}$ ). The keto group on C-5 seems to have a key role. In fact the natural compound 3-epi illudol (10), whose difference from tsugicoline is the absence of this group, shows lower activity. The activity is maintained if the carbonyl group is substituted with another polar group such as the hydroxyl group (17) or an unsubstituted oxime (19a). On the contrary, the introduction of bulky or lypophilic groups such as a methyl (19b) or a benzyl (19c) causes a decrease of activity.

In conclusion, Tsugicoline A, a sesquiterpenoid with protoilludane skeleton, was identified as a potential lead structure for the treatment of M. haemolytica and E. coli infections. Optimization of Tsugicoline A extraction from the fungus E. tsugicola allowed us to synthesize a series of derivatives and to develop preliminary structure-activity relationships studies to delineate the essential structural requirements for antimicrobial activity against $M$. haemolytica.

\section{ACKNOWLEDGEMENTS}

We are indebted to Professor G Nasini, who spent his life on fungal secondary metabolite characterization and continues to provide insight and support with his thoughtful comments.

1 Schüffler, A. \& Anke, T. Secondary Metabolites of Basidiomycetes. in The Mycota (eds Anke, T. \& Weber, D.) XV 209-231 (Springer, Berlin, Heidelberg, New York, 2009).

2 Aly, A. H., Debbab, A. \& Proksch, P. Fifty years of drug discovery from fungi. Fungal. Divers. 50, 3-19 (2011).

3 Pulcini, C. et al. Forgotten Antibiotics: An Inventory in Europe, the United States, Canada, and Australia. Clin. Infect. Dis. 54, 268-274 (2012).

4 Van der Poll, T. \& Opal, S. M. Pathogenesis, treatment, and prevention of pneumococcal pneumonia. Lancet. 374, 1543-1556 (2009).
5 Takeuchi, T., linuma, H., Momose, I. \& Matsui, S. (Jpn Kokai Tokkyo Koho). Antibiotic pasteurestin A and B and their manufacture with Agrocybe cylindracea. JP 2002212137 (2002).

6 Rice, J. A., Carrasco-Medina, L., Hodgins, D. C. \& Shewen, P. E. Mannheimia haemolytica and bovine respiratory disease. Anim. Health Res. Rev. 8, 117-128 (2007).

7 Kogl, M., Brecker, L., Warrass, R. \& Mulzer, J. Novel protoilludane lead structure for veterinary antibiotics: total synthesis of pasteurestins $A$ and $B$ and assignment of their configurations. Eur. J. Org. Chem. 16, 2714-2730 (2008).

8 Arnone, A., Cardillo, R., Di Modugno, V. \& Nasini, G. Secondary mould metabolites. Part 29. Isolation and structure elucidation of Candicansol, 3-epi-illudol and 1-0Acetyl-3-epi-illudol, novel sesquiterpenoids from Clitocybe candicans, and absolute configuration of 3-epi-illudol. J. Chem. Soc. Perkin Trans. 1, 1995-2000 (1989).

9 Arnone, A., Brambilla, U., Nasini, G. \& Vajna de Pava, O. Isolation and structure elucidation of tsugicolines A-D, novel protoilludane sesquiterpenes from Laurilia tsugicola. Tetrahedron 51, 13357-13364 (1995).

10 Arnone, A., Nasini, G., Assante, G., Roeijmans, H. J. \& Van Eijk, G. W. Secondary mould metabolites. Part XVIII. Sulcatine, a norsesquiterpene from the fungus Laurilia sulcata. Phytochemistry 26, 1739-1742 (1987).

11 Arnone, A., Nasini, G., Assante, G. \& Van Eijk, G. W. Secondary mould metabolites. 35. Three sesquiterpenes produced by the fungus Laurilia sulcata. Phytochemistry 31 , 2047-2050 (1992).

12 Arnone, A., De Gregorio, C., Meille, S. V., Nasini, G. \& Sidoti, G. Tsugicoline E, a new polyoxygenated protoilludane sesquiterpene from the fungus Laurilia tsugicola. J. Nat. Prod. 62, 51-53 (1999).

13 Arnone, A., Cardillo, R. \& Nasini, G. Secondary mold metabolites. Part 19. Structure elucidation and absolute configuration of melledonals B and C, novel antibacterial sesquiterpenoids from Armillaria mellea. X-ray molecular structure of melledonal C. J. Chem. Soc. Perkin Trans. 1 3, 503-510 (1988).

14 Arnone, A., Candiani, G., Nasini, G. \& Sininsi, R. Isolation and structure elucidation of new sesquiterpenes of protoilludane origin from the fungus Clavicorona divaricata. Tetrahedron 59, 5033-5038 (2003).

15 Nair, M. S., Takeshita, H., McMorris, T. C. \& Anchel, M. Metabolites of Clitocybe illudens. IV. Illudalic acid, a sesquiterpenoid, and illudinine, a sesquiterpenoid alkaloid. J. Org. Chem. 34, 240-243 (1969).

16 Anchel, M., Hervey, A. \& Robbins, W. J. Antibiotic substances from basidiomycetes: VII. Clitocybe illudens. Proc. Natl Acad. Sci. USA 36, 300-305 (1950).

17 Arnone, A., De Gregorio, C., Nasini, G. \& Vajna de Pava, O. Secondary mould metabolites: part 53. Transformation of the protoilludane sesquiterpene tsugicoline A into a sterpurane derivative and its microbiological reduction. J. Chem. Soc. Perkin Trans. 1, 1523-1525 (1997).

18 Arnone, A., De Gregorio, C., Mele, A., Nasini, G. \& Vajna de Pava, O. Secondary mould metabolites. Part 58. Modifications in basic conditions and Michael additions of the protoilludane sesquiterpene tsugicoline $A$; some implications for the biogenesis of the sesquiterpenoids produced by Basidiomycetes. J. Chem. Soc. Perkin Trans. 1, 745-751 (2000).

19 Shiono, Y., Suzuki, S., Murayama, T., Ikeda, M. \& Abe, Y. Protoilludane sesquiterpenoids, echinocidins $C$ and $D$ produced by a decay causing fungal strain Echinodontium tsugicola. Z. Naturforsch. 60, 449-452 (2005).

20 Dallavalle, S., Merlini, L., Beretta, G. L., Tinelli, S. \& Zunino, F. Synthesis and cytotoxic activity of substituted Luotonin A derivatives. Bioorg. Med. Chem. Lett. 14, 5757-5761 (2004).

Supplementary Information accompanies the paper on The Journal of Antibiotics website (http://www.nature.com/ja) 